\title{
A GENERALIZED NONLINEAR SUMS-DIFFERENCE INEQUALITY AND ITS APPLICATIONS
}

\begin{abstract}
ZIZUN LI
Abstract. In this paper, we established a generalized sums difference inequality with two variables, which included five sums. By using a lemma, we turned the inequality into a common form. We applied our result to boundary value problem of a partial difference equation for boundedness, uniqueness.
\end{abstract}

Mathematics subject classification (2010): 34B15, 26D15, 26D10.

Keywords and phrases: Sum-difference inequality, monotonicity, boundary value problem, boundedness.

\section{REFERENCES}

[1] R. P. Agarwal, Difference equations and inequalities, Marcel Dekker, New York, 1992.

[2] R. P. Agarwal, S. Deng AND W. Zhang, Generalization of a retarded Gronwall-like inequality and its applications, Appl. Math. Comput. 165 (2005), 599-612.

[3] R. P. AgARWAL, Y. H. Kim AND S. K. SEN, New retarded integral inequalities with applications, J. Inequ. Appl., 2008 (2008), 15 pages.

[4] R. Bellman, The stability of solutions of linear differential equations, Duke Math. J. 10 (1943), 643-647.

[5] D. Bainov And P. Simeonov, Integral Inequalities and Applications, Kluwer Academic, Dordrecht, 1992.

[6] I. A. BIHARI, A generalization of a lemma of Bellman and its application to uniqueness problem of differential equation, Acta Math. Acad. Sci. Hung. 7 (1956), 81-94.

[7] C. J. Chen, W. S. Cheung And D. ZhaO, Gronwall-Bellman-Type integral inequalities and applications to BVPs, J. Inequ. Appl. 2009 (2009), Art. ID 258569, 15 pages.

[8] W. S. Cheung, Some new nonlinear inequalities and applications to boundary value problems, Nonlinear Anal. 64 (2006), 2112-2128.

[9] W. S. Cheung, Some retarded Gronwall-Bellman-Ou-Iang-type inequalities and applications to initial boundary value problems, preprint.

[10] W. S. Cheung AND J. Ren, Discrete non-linear inequalities and applications to boundary value problems, J. Math. Anal. Appl. 319 (2006), 708-724.

[11] S. K. Choi, S. Deng, N. J. Koo And W. Zhang, Nonlinear Integral Inequalities of Bihari-Type without Class H, Math. Inequalities Appl. 8 (2005), 4: 643-654.

[12] S. S. Dragomir AND Y. H. KIM, Some integral inequalities for functions of two variables, Electr. J. Diff. Eqns. 2003 (2003), no. 10, 1-13.

[13] Q. H. Feng, F. W. Meng And B. S. Fu, Some new generalized Volterra-Fredholm type finite difference inequalities involving four iterated sums, Appl. Math. Comput. 219 (2013), 8247-8258.

[14] T. H. GRONWALL, Note on the derivatives with respect to a parameter of the solutions of a system of differential equations, Ann. of Math. 20 (1919), 292-296.

[15] Y. H. Kıм, Gronwall, Bellman and Pachpatte type integral inequalities with applications, Nonlinear Anal. 71 (2009), 2641-2656.

[16] O. Lipovan, Integral inequalities for retarded Volterra equations, J. Math. Anal. Appl. 322(2006), 349-358. 
[17] Q. H. Ma AND E. H. YAng, Some new Gronwall-Bellman-Bihari type integral inequalities with delay, Periodica Mathematica Hungarica, 44 (2002), 225-238.

[18] Q. H. MA AND W. S. Cheung, Some new nonlinear difference inequalities and their applications, J. Comput. Appl. Math., 2007, 202: 339-351.

[19] B. G. PaChPATtE AND S. G. DeO, Stability of discrete time systems with retarded argument, Utilitas Math. 4 (1973), 15-33.

[20] B. G. PAChPatTE, Inequalities for Differential and Integral Equations, Academic Press, New York, 1998.

[21] B. G. Pachpatte, A note on some discrete inequalities, Tamsui Oxford Journal of Mathematical Sciences, 21 (2) (2005), 183-190.

[22] H. Y. QIn, X. ZUO ANS J. W. LiU, Some New Generalized Retarded Gronwall-Like Inequalities and Their Applications in Nonlinear Systems, J. Contr. Sci. Engr., 2016 (2016), Art. ID 9527680, 8 pages.

[23] W. S. WANG, A generalized sum-difference inequality and applications to partial Difference equations, Adv. Difference Equ., 2008 (2008), 12 pages.

[24] W. S. WANG, X. L. ZHOU, An extension to nonlinear sum-difference inequality and applications, Adv. Difference Equ., 2009 (2009), 17 pages.

[25] W. S. WANG, Z. Z. Li AND W. S. ChEUNG, Some new nonlinear retarded sum-difference inequalities with applications, Adv. Difference Equ., 2011 (2011), 11 pages.

[26] D. Willett AND J. S. W. WonG, On the discrete analogues of some generalizations of Gronwall's inequality, Monatsh. Math. 69 (1965), 362-367.

[27] W. Zhang And S. Deng, Projected Gronwall-Bellman's inequality for integrable functions, Math. Comput. Modelling 34 (2001), 394-402.

[28] B. Zheng AND B. Fu, Some Volterra-Fredholm type nonlinear discrete inequalities involving four iterated infinite sums, Adv. Difference. Equ 2012 (2012), 18 pages. 